\title{
Prevalence of the Anterior Occipital Sulcus in the Human Brain: Anatomical Study
}

\author{
Bassam MJ Addas, MD, ChB, FRCSC \\ Department of Surgery, Division of Neurosurgery, Faculty of Medicine \\ King Abdulaziz University, Jeddah, Saudi Arabia
}

\section{Correspondence}

Dr. Bassam MJ Addas

P.O. Box 80215, Jeddah 21589, Saudi Arabia

e.M: bassamaddas@yahoo.com

Submission: 21 June 2015

Accepted: $\quad 05$ Oct. 2015

\section{Citation}

Addas, BMJ. Prevalence of the anterior occipital sulcus in the human brain: anatomical study. JKAU Med Sci 2016; 23 (1): 19-22. DOI: 10.4197/ Med. 23.1.3

\begin{abstract}
The objective of this article is to investigate the prevalence of the anterior occipital sulcus in the human brain. The external surface of 25 consecutive formalin fixed brains ( 50 hemispheres) were examined for the presence of the anterior occipital sulcus. The anterior occipital sulcus was identified in 11 (22\%) hemispheres, seven on the right side and 4 on the left side. The sulcus length ranged from $1-5 \mathrm{~cm}$ with a mean length of $2.89 \mathrm{~cm}$. The mean distance from the occipital lobe tip to the anterior occipital sulcus was $4.75 \mathrm{~cm}$ on the right side and 5 $\mathrm{cm}$ on the left side. The anterior occipital sulcus can be infrequently encountered in human brains (22\%); when present it represents the posterior limit of the temporal lobe and the anterior limit of the occipital lobe.
\end{abstract}

\section{Keywords}

Anterior occipital sulcus; Surface anatomy; Occipital lobe

\section{Introduction}

$T$ he anterior occipital sulcus (AOS) is seldom mentioned in general neuroanatomy books. The AOS is described as the sulcus that stems off the inferior temporal sulcus or the sulcus that originates at the region of the pre-occipital notch and ascends vertically either as a straight or curved line $e^{[1]}$.

The pre-occipital notch is an indentation on the infero-lateral border of the brain, $5 \mathrm{~cm}$ anterior to the tip of the occipital lobe ${ }^{[2]}$. The posterior limit of the temporal lobe is designated arbitrarily. It has been described as an imaginary line drawn from the end of the Sylvian fissure to a point midway and perpendicular to a line connecting the parieto-occipital sulcus superiorly to the pre-occipital notch inferiorly. This line is used as a result of the absence of a consistent sulcus demarcating the boundaries between the temporal and the occipital lobe. Defining the anatomy at the temporo-occipital junction is important as it separates a highly eloquent occipital cortex from a much less eloquent posterior temporal lobe cortex particularly on the right side, making surgical approaches to this region more defined and safe. The aim of this study is to define the presence, position and length of the anterior occipital sulcus and hence the posterior limit of the temporal lobe and the anterior limit of the occipital lobe.

\section{Methods}

Examination of the anterior occipital sulcus was performed on 25 human brains ( 13 males and 12 females, mean age 61 years, range 42-71). None of the brains were from subjects with known neurological or psychiatric disease noted in their clinical history. Brains were removed from subjects within 48 hours of their demise and placed in $4 \%$ solution of formaldehyde for a period of at least 6 weeks. Fixation was performed by suspending the brains on the basal arteries (circle of Willis) to avoid distortion of the lateral surface of the brain. The brain was cleaned of its lepto-meninges 
and blood vessels with care and with preservation of the cortical architecture. Identification of the anterior occipital sulcus was made according to the known surface anatomy described by the anatomy text books ${ }^{[1-3]}$. When present, measurements were made including the sulcus length, distance from the occipital lobe tip and distance from the temporal lobe tip.

\section{Results}

Anterior occipital sulcus (Fig. 1) was found in 11 (22\%) hemispheres, seven on the right side and four on the left side. The mean length of the AOS was $2.89 \mathrm{~cm}$ (range 1-5 cm). The mean distance between the AOS and the tip of the occipital lobe was $4.75 \mathrm{~cm}$ (range 3.8-5.5 cm). The mean distance between the AOS and the temporal lobe tip was $9.1 \mathrm{~cm}$ (range 9-11 cm). Results of measurements were noted and tabulated (Table 1). In only one hemisphere the AOS was found bilaterally. When present, the AOS was continuous in all specimens and consistently originated from the preoccipital notch.

\section{Discussion}

The sulcus anatomy of the human brain is both complex and highly variable. The occipital lobe region, particularly the lateral surface, is a controversial brain region with inconsistent sulcal anatomy. The transverse sulcal anatomy of the occipital lobe is much more consistent than the vertical sulcal anatomy. Malikovic et al. ${ }^{[4]}$ reported the presence of AOS in $100 \%$ of 30 hemispheres examined ${ }^{[4]}$. However in his report, AOS was considered to be present whether it originated from the parieto-occipital notch or as ascending ramus of the inferior temporal sulcus. Ono et al. ${ }^{[5]}$ reported an incidence of $28 \%-48 \%$ of the examined hemispheres and others did not report the presence of AOS in the anatomical studies of the occipital lobe ${ }^{[6]}$.

There are many factors ${ }^{[4]}$ responsible for its variability such as: (1) Degree of regional cortical folding, (2) the presence or absence of the sulcus, (3) sulcal segmentation, (4) differences in length and depth, (5) diversity of sulcal origin and (6) intrasulcal geometry. The presence of consistent sulci like the

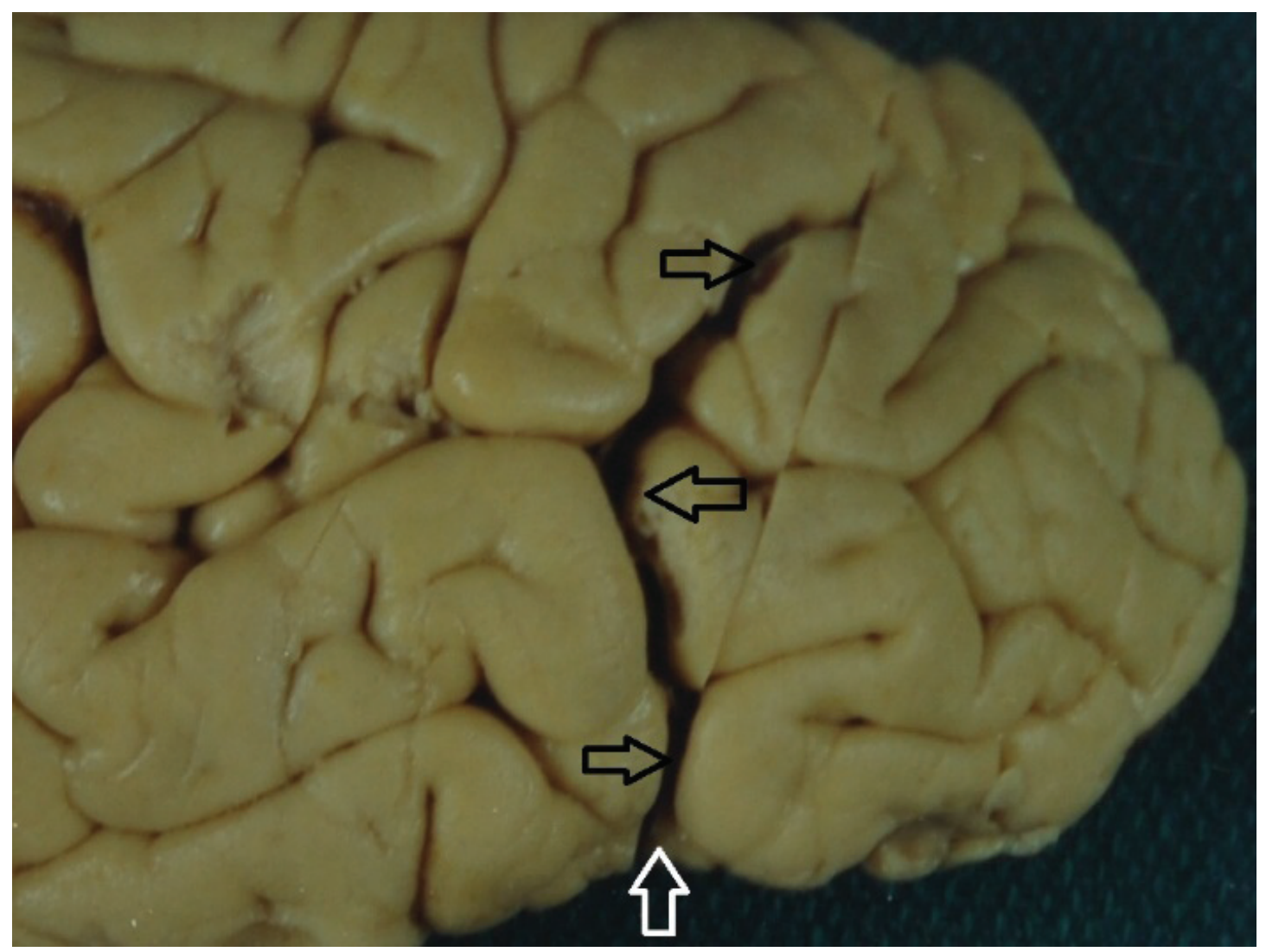

Figure 1. Photograph of a formalin fixed left hemisphere showing the anterior occipital sulcus (Black arrows) originating from the preoccipital notch (white arrow) 
Table 1. List of the hemispheres with anterior occipital sulcus with the measured length and distance from the temporal lobe tip and occipital lobe tip

\begin{tabular}{|c|c|c|c|c|}
\hline $\begin{array}{c}\text { Number of } \\
\text { Specimen }\end{array}$ & $\begin{array}{c}\text { Length of the Sulcus } \\
\text { (Right Side) }\end{array}$ & $\begin{array}{c}\text { Length of the Sulcus } \\
\text { (Left Side) }\end{array}$ & $\begin{array}{c}\text { Distance From the Occipital } \\
\text { Lobe Tip }\end{array}$ & $\begin{array}{c}\text { Distance from the Temporal } \\
\text { Lobe Tip }\end{array}$ \\
\hline 4 & 2.3 & & 5 & 9.5 \\
\hline 5 & 3 & & 5 & 10 \\
\hline 6 & 4 & 4 & 5.5 & 9 \\
\hline 8 & 1.5 & 2 & 5.7 & 11 \\
\hline 9 & 1 & & 5 & 10 \\
\hline 10 & & 5 & 5 & 10 \\
\hline 11 & & 2 & 4.8 & 9.5 \\
\hline 13 & 3 & 4.8 & 10.5 \\
\hline 15 & 4 & & 3.8 & 11 \\
\hline 22 & & & 5 & 10 \\
\hline
\end{tabular}

Sylvian or the Rolandic sulci makes intra-operative identification of the nearby anatomical landmarks relatively easy. In the absence of well-formed sulcus anatomy, the surgeons become less certain and the possibility of error rises.

The current application of intra-operative neuronavigation tools has improved the intraoperative localization but cannot substitute the value of consistent sulci. Furthermore the available MRI of the brain does fail to show the exact definition of the $\operatorname{AOS}^{[7]}$.

It is worth mentioning that there is no posterior occipital sulcus and the most consistent sulci on the lateral aspect of the occipital lobe are the lateral sulcus, and the transverse sulcus. The lunate sulcus is present in $60 \%$ of cases. The presence of the AOS does not substitute for the presence of the consistent sulci.

This current study demonstrates the existence of AOS in only $22 \%$ of cases. When present it defines the posterior boundary of the temporal lobe, and when absent, a point $5 \mathrm{~cm}$ from the occipital lobe tip can be considered as an arbitrary point defining the anterior limit of the occipital lobe.

\section{Conflict of Interest}

The author has no conflict of interest.

\section{Disclosure}

The author did not receive any type of commercial support either in forms of compensation or financial for this study. The author has no financial interest in any of the products or devices, or drugs mentioned in this article.

\section{Ethical Approval}

Obtained.

\section{References}

1. Duvernoy HM. Surface anatomy of the brain. In: The Human Brain. Surface Three-Dimensional Sectional Anatomy. Duvernoy, ed New York: Springer-Verlag Wien, 1991.

2. Gray H, Williams PL, Warwick R. Gray's Anatomy. Williams PL, Warwick R, eds. 36 edn. Edinburgh: Churchill Livingstone; 1980. 636-637

3. [No authors listed]. Topography of the cerebral hemispheres. In: The Human Nervous System: An Anatomical Viewpoint. Barr ML, Kiernan JA, ed. $6^{\text {th }}$ edn. Philadelphia, PA: Lippincott, 1993.

4. Malikovic A, Vucetic B, Milisavljevic M, Tosevski J, Sazdanovic P, Milojevic B, Malobabic S. Occipital sulci of the human brain: variability and morphometry. Anat Sci Int 2012; 87(2): 61-70

5. Ono M, Kubik S, Abernathy CD. Atlas of cerebral sulci. Stuttgart: Thieme Verlag. 1990; 62-74

6. Flores LP. Occipital lobe morphological anatomy: anatomical and surgical aspects. Arq Neuropsiquiatr 2002; 60(3-A): 566-571.

7. Iaria G, Petrides M. Occipital sulci of the human brain: variability and probability maps. J Comp Neurol 2007; 501(2): 243-259. 


\title{
إنتشار الأخدود القفوي الأمامي فى المخ البشري: دراسه تشريحيه
}

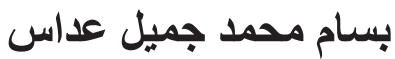

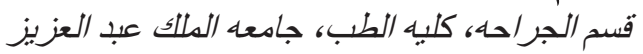 \\ جله ـ المدلكه العربيه السعوديه .
}

المستخلص. تحديد نسبه الأخدود القفوي الأمامي فى المخ البشري. تم فحص مب مخ بشري (.0 فصد) محفوظ في

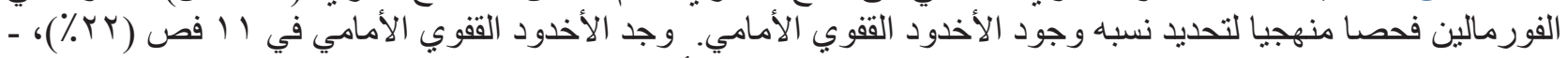

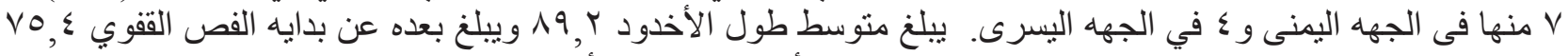

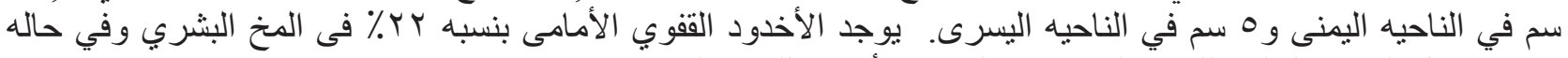
وجوده يمثل الحدود الخلفيه للفص الصديه في والنيه الحدود الأماميه للفص القفوي. 